NASA Technical Memorandum 89849

\title{
Boron Nitride: Composition, Optical Properties, and Mechanical Behavior
}

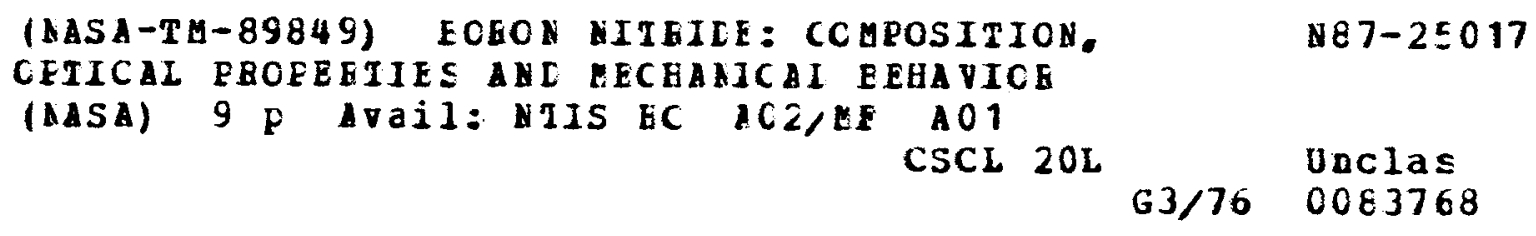

John J. Pouch, Samuel A. Alterovitz, Kazuhisa Miyoshi, and Joseph D. Warner

Lewis Research Center

Cleveland, Ohio

Prepared for the

1987 Spring Meeting of the Materials Research Society

Anaheim, California, April 21-25, 1987

\section{nNSA}


BORON NITRIDE: COMPOSITION, OPTICAL PROPERTIES, AND MECHANICAL BEHAVIOR

\author{
John J. Pouch, Samuel A. Alterovitz, \\ Kazuhisa Miyoshi, and Joseph D. Warner \\ National Aeronautics and Space Administration \\ Lewis Research Center \\ Cleveland, Ohio 44135
}

\title{
SUMMARY
}

A low energy ion beam deposition technique was used to grow boron nitride films on quartz, germanium, sllicon, gallium arsenide, and indium phosphide. The film structure was amorphous with evidence of a hexagonal phase. The peak boron concentration was 82 at $\%$. The carbon and oxygen impurtties were in the 5 to 8 at $\%$ range. Boron-nitrogen and boron-boron bonds were revealed by $x$-ray photoelectron spectroscopy. The index of refraction varied from 1.65 to 1.67 for films deposited on the III-V compound semiconductors. The coefficient of friction for boron nitride in sliding contact with diamond was less than 0.1 .

\section{INTRODUCTION}

Thin boron $n i t r i d e(B N)$ films can be useful for passivation, as gate dielectrics, and masks in $x$-ray lithography. BN, a high temperature, wearresistant, corrosion-resistant material, is chemically inert. Several techniques are used to synthesize BN: chemical vapor deposition (refs. 1 and 2), sputter deposition (ref. 3), ion implantation (ref. 4), reactive evaporation (ref. 5), and ion beam deposition (ref. 6).

In the present study, the compositional and optical properties, as well as the mechanical characteristics of the films are reported.

\section{EXPERIMENTAL}

The BN samples were deposited on quartz, germanium, silicon, n-type gallium arsenide, and n-type indium phosphide substrates. The ion beam deposition technique utilized a borazine plasma. The ion bombardment energies were 150 and $500 \mathrm{eV}$, and the substrate temperatures were 200 and $350{ }^{\circ} \mathrm{C}$. The films adhered to all the substrates.

The microstructural data for $B N$ were obtained by means of transmission electron microscopy (TEM) and electron diffraction. The film was mechanicaliy removed from the substrate for the microstructural studies by ion etching. (The film could not be pried off in the same manner as pyrolytic BN.)

The chemical bonding states of boron, nitrogen, carbon, and oxygen were studied by means of $x$-ray photoelectron spectroscopy (XPS). The $x$-ray source was an aluminum anode. The measurements were taken at a power of $400 \mathrm{~W}$. The binding energy of the gold $4 \mathrm{f7/2}$ peak was set at $83.8 \mathrm{eV}$.

The BN film surface was analyzed by Auger electron spectroscopy (AES). Depth profiling was performed by rastering of a focused, $3 \mathrm{keV}$ argon ion beam. 
The stoichiometry of the film was calculated using standard elemental sensitivity factors (ref. 7).

The transmission spectrum for BN deposited on a germanium multiple internal reflection (MIR) plate was measured from 2.5 to $50 \mu \mathrm{m}$ by spectrophotometry. In addition, absorption studies of $\mathrm{BN}$-on-quartz were made in the 0.19 to $3.2 \mu \mathrm{m}$ range.

Refractive indices, extinction coefficients, and film thicknesses were determined using a rotating analyzer ellipsometer. A Xe arc lamp produced the incident light. The multiple angles and wavelengths technique was applied to the experimental data (ref. 8). At least five angles of incidence were utilized at each wavelength.

Single-pass scratch tests of the BN surface were conducted in a friction and wear apparatus operating in air. One end of a rod contained the diamond pin. Dead weights were placed in a pan located at the other end of the rod, thus permitting the film to be loaded. The diamond and BN surfaces were brought into contact and loaded. The contact time, prior to a sliding experi-. ment, was $30 \mathrm{sec}$. The total sliding distance was approximately $10 \mathrm{~mm}$; the sliding velocity was of the order of $12 \mathrm{~mm} / \mathrm{min}$.

\section{RESULTS ANO DISCUSSIONS}

Results from TEM and electron diffraction studies indicate that the films are predominantly amorphous. In addition, a crystalline phase, exhibiting features in the 8 to $30 \mathrm{~nm}$ range, is identified. The diffuse rings, noted in the electron diffraction pattern, are due to hexagonal $B N$.

XPS scans (pass energy, $50 \mathrm{eV}$ ) of the $B(1 \mathrm{~s}), N(1 \mathrm{~s}), C(15)$, and $0(1 \mathrm{~s})$ photoelectron 1 ines for the as-deposited $B N$ film surface (InP substrate) confirm the AES data. After argon ion sputtering for $65 \mathrm{~min}$, the $\mathrm{C}(1 \mathrm{~s})$ line is at an energy representative of a carbide (ref. 9 ); the $0(1 \mathrm{~s})$ peak, related to $\mathrm{B}_{2} \mathrm{O}_{3}$, is diminished (ref. 9). The $\mathrm{B}(1 \mathrm{~s})$ spectrum results from $\mathrm{B}-\mathrm{N}$ and $\mathrm{B}-\mathrm{B}$ bonds (ref. 10). The $N(1 s)$ structure is principally due to B-N (ref. 10).

AES analysis of the as-deposited $B N$ f 1 lm indicates the presence of the $B(K L L)$ and $N(K L L)$ peaks, as well as the adsorbed $C(K L L)$ and $0(K L L)$ contaminants. A depth profile of the elements is presented in figure 1 for $B N$ deposited on GaAs (substrate temperature, $200{ }^{\circ} \mathrm{C}$; ion beam energy, $500 \mathrm{eV}, \mathrm{film}$ thickness, $1290 \AA)$. The $B$ and $N$ signals increase after the contamination layer is removed. The $C$ and 0 impurities are in the 5 to 8 at $\%$ range. Discharges occurring on the walls within the deposition chamber can produce impurity incorporation (ref. 6). The B concentration is approximately 75 at $\%$ near the film surface, and drops to about 52 at $\%$ near the BN-GaAs interface. In contrast, the $N$ concentration ranges from 6 to 8 at $\%$. The $C, 0$, and $N$ levels peak in the interfacial region. Similar results are obtained for a 1160 thick BN film deposited on InP; the maximum B concentration is 82 at $\%$. The AES results for films deposited on GaAs and InP substrates are summarized in table I. We used the elemental sensitivity factors to calculate the atomic concentrations. Another possibility is to use the sensitivity factors derived from stoichiometric $\mathrm{BN}$; however, those factors are different from ours, with the elemental factor giving more weight to $B$ (ref. 4). In the present case, we have a material which is neither elemental B, N, nor BN. Results obtained 
by XPS indicate B-N and B-B bonds. Thus, neither choice of sensitivity factors will be accurate. The elemental factors were selected in order to be consistent with the other published work (ref. 4).

Several absorption bands are found in the transmission spectrum for $B N-$ on-Ge. The peak at $6.9 \mu \mathrm{m}$ is due to the $\mathrm{B}-\mathrm{N}$ bending mode (ref. 5). The maximum near $6.5 \mu \mathrm{m}$ is associated with $N=0$. The $B-H$ vibration is observed at $4 \mu \mathrm{m}$ (ref. 5). A broad structure in the vicinity of $2.9 \mu \mathrm{m}$ results from $0-H$.

The Tauc plot, i.e., $\sqrt{A E}$ versus $E$ is presented in figure 2. The absorbance is $A$, and the photon energy is $E$. The sample is BN-on-quartz (substrate temperature, $200^{\circ} \mathrm{C}$; ion beam energy, $500 \mathrm{eV}$ ). According to an existing theory of amorphous solids, a linear relationship between $\sqrt{A E}$ and $E$ can be used to determine $E_{0}$, the optical band gap (ref. 11). Referring to the data shown in figure 2, we find $E_{0}$ to be of the order of $4.8 \mathrm{eV}$. Our previous results indicate that for $B / N$ of the order of $2, E_{0}$ is $5.1 \mathrm{eV}$ (ref. 12). Therefore, there is a trend which suggests that $E_{0}$ decreases as the $B$ concentration increases, but at a lower rate than the published data (ref. 3).

The ellipsometric results for ion beam deposited BN-on-GaAs (substrate temperature, $200{ }^{\circ} \mathrm{C}$; ion beam energy, $500 \mathrm{eV}$ ) are summarized in table II. According to the AES measurements, the $f 17 \mathrm{~m}$ is nonstoichiometric. Alternatively, the film can be referred to as heavily-doped $B$. The refractive index varies from 1.66 to 1.67 for the wavelength region investigated. The maximum absorption coefficient is approximately $1.29 \times 10^{4} \mathrm{~cm}^{-1}(4300 \mathrm{~A})$. The refractive index for $\mathrm{BN}$ - on-InP (substrate temperature, $200^{\circ} \mathrm{C}$; ion beam energy, $500 \mathrm{eV}$ ) is in the 1.65 to 1.67 range (see table I). Discernible absorption is observed at $5000 \AA$. The maximum absorption coefficient is of the order of $0.35 \times 10^{4} \mathrm{~cm}^{-1}(4000 \AA)$. At fixed wavelength, the absorption coefficient for the $B N$ film on InP is smaller than that found for BN-on-GaAs. It is interesting to note that the refractive index for $B N$-on-Si (substrate temperature, $200{ }^{\circ} \mathrm{C}$; ion beam energy, $150 \mathrm{eV}$ ) changes from about 1.71 to 1.81 over a similar wavelength region (ref. 12). The maximum absorption coefficient is estimated to be $0.16 \times 10^{4} \mathrm{~cm}^{-1}$.

The coefficient of friction as a function of load is shown in figure 3 for the $S i$ substrate, and $B N$-on-Si at two temperatures: 200 and $350{ }^{\circ} \mathrm{C}$ ( 1 on beam energy, $150 \mathrm{eV}$ ). The coefficlent of friction is greater for the diamond pin in contact with the bare Si. When the diamond contacts the BN surface, the coefficient of friction is reduced. The coefficient is relatively insensitive to the substrate temperature. The contact area between the diamond and $B N$ causes a permanent groove to be formed in the film. Complex elastic and plastic processes are responsible for the wear track. The critical load required to fracture $S i$ in sliding contact with diamond is $5 \mathrm{~N}$. Moreover, when a BN film is deposited on Si, the critical load needed to fracture the si surface is increased to $7 \mathrm{~N}$.

\section{CONCLUSIONS}

Ion beam deposited thin BN films can contain up to 82 at \% boron. Carbon and oxygen impurities are also present. The BN structure is amorphous, with evidence of a hexagonal phase. Boron-nitrogen and boron-boron bonds are 
detected. Although the films are boron-rich, the optical band gaps are of the order of $4.8 \mathrm{eV}$. We find that the optical band gap decreases as the boron content increases, but at a slower rate than the published results (ref. 3 ). The measured index of refraction varies from 1.65 to 1.67. The coefficient of friction for $B N$ in sliding contact with diamond is less than 0.1 . The critical load needed to fracture the silicon surface is increased by 40 percent when a BN film is used.

\section{ACKNOWLEDGMENTS}

The authors would like to thank Dr. W. Halverson of Spire Corporation for providing the samples, and $N$. Shoemaker for assistance with some of the measurements.

\section{REFERENCES}

1. M.J. Rand and J.F. Roberts, J. Electrochem. Soc. 115, 423 (1968).

2. M. Hirayama and K. Shohno, J. Electrochem. Soc. 122, 1671 (1975).

3. M.D. Wiggins, C.R. Aita, and F.S. Hickernel1, J. Vac. Sci. Technol. A2, 322 (1984).

4. L. Guzman, F. Marchetti, L. Calliari, I. Scotoni, and F. Ferrari, Thin Solid Films 117, L63 (1984).

5. K.L. Chopra, V. Agarwa 1, V.D. Vankar, C.V. Deshpandey, and R.F. Bunshah, Thin Solid Ftlms 126, 307 (1985).

6. W. Halverson and D.T. Quinto, J. Vac. Sci. Technol. A3, 2141 (1985).

7. L.E. Davis, N.C. MacDonald, P.W. Palmberg, G.E. Riach, and R.E. Weber, Handbook of Auger Electron Spectroscopy, 2nd ed., Perkin-Elmer Corp., Eden Prairie, p. 13, (1978).

8. S. Alterovitz, G.H. Bu-Abbud, J.A. Woollam, and D.C. Liu, J. Appl. Phys. 54, 1559 (1983).

9. K. Miyoshi, D.H. Buckley, and T. Spalvins, J. Vac. Sct. Technol. A3, 2340 (1985).

10. C.D. Wagner, W.M. Riggs, L.E. Davis, J.F. Moulder, and G.E. Muilenberg, Handbook of X-Ray Photoelectron Spectroscopy, 1 st ed. Perkin-Elmer Corp., Eden Prairie, p. 36, (1979).

11. J.J. Pouch, S.A. Alterovitz, J.D. Warner, D.C. Liu, and W.A. Lanford, in "Thin Flims: The Relationship of Structure to Properties," C.R. Aita and K.S. SreeHarsha, eds., Materials Research Society, Pittsburgh, p. 201 (1985). 
12. S.A. Alterovitz, J.D. Warner, D.C. Liu, and J.J. Pouch, in Proceedings of the Symposium on Dielectric Films on Compound Semiconductors, V.J. Kapoor, D.J. Connolly, and Y.H. Wong, eds., Electrochemical Society, Pennington, p. $59(1986)$.

TABLE I. - AES RESULTS FOR BN FILMS DEPOSIIED

ON GaAS AND InP

[Substrate temperature, $200{ }^{\circ} \mathrm{C}$;

ion beam energy, $500 \mathrm{eV}$.]

\begin{tabular}{|c|c|c|c|}
\hline Substrate & $\begin{array}{c}\text { Film thickness, } \\
\AA\end{array}$ & $\begin{array}{c}\text { Maximum } \\
\% \mathrm{~B}\end{array}$ & $\begin{array}{c}\text { Maximum } \\
\% \mathrm{~N}\end{array}$ \\
\hline GaAs & 1290 & 75 & 8 \\
InP & 1160 & 82 & 8 \\
\hline
\end{tabular}

TABLE II. - REFRACTIVE INDICES, $n$, AND EXTINCTION COEFFICIENTS, $k$,

FOR BN FILMS DEPOSITED ON GaAs AND InP

[The wavelength is $\lambda$. Substrate temperature, $200{ }^{\circ} \mathrm{C}$; ion beam energy, $500 \mathrm{eV}$.

\begin{tabular}{|c|c|c|c|c|}
\hline \multirow{2}{*}{$\left.\begin{array}{c}\lambda, \\
A\end{array}\right)$} & \multicolumn{2}{|c|}{ BN-on-GaAS } & \multicolumn{2}{c|}{ BN-on-InP } \\
\cline { 2 - 5 } & $n$ & $k$ & $n$ & $k$ \\
\hline 4000 & 1.667 & 0.035 & 1.669 & 0.001 \\
4300 & 1.661 & .044 & 1.664 & .009 \\
4600 & 1.672 & .045 & 1.660 & .004 \\
5000 & 1.663 & .050 & 1.656 & .004 \\
5500 & 1.666 & .042 & 1.653 & $\ldots .$. \\
6000 & 1.662 & .033 & 1.648 &..- \\
\hline
\end{tabular}




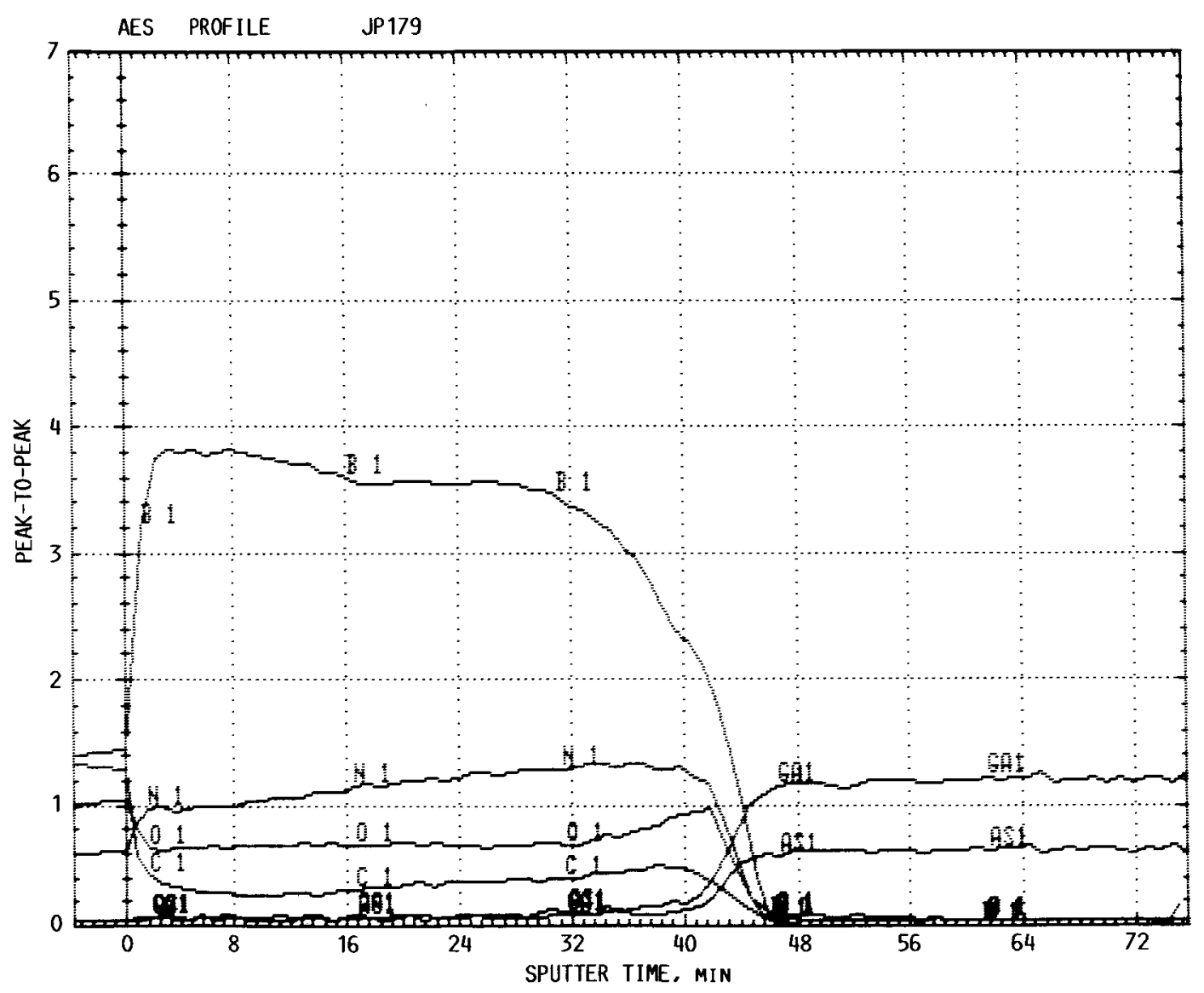

FIGURE 1. - AUGER DEPTH PROFILE OF ION BEAM DEPOSITED BN-ON-GAAS. SUBSTRATE TEMPERATURE, $200^{\circ} \mathrm{C}$; ION BEAM ENERGY, $500 \mathrm{EV}$. 


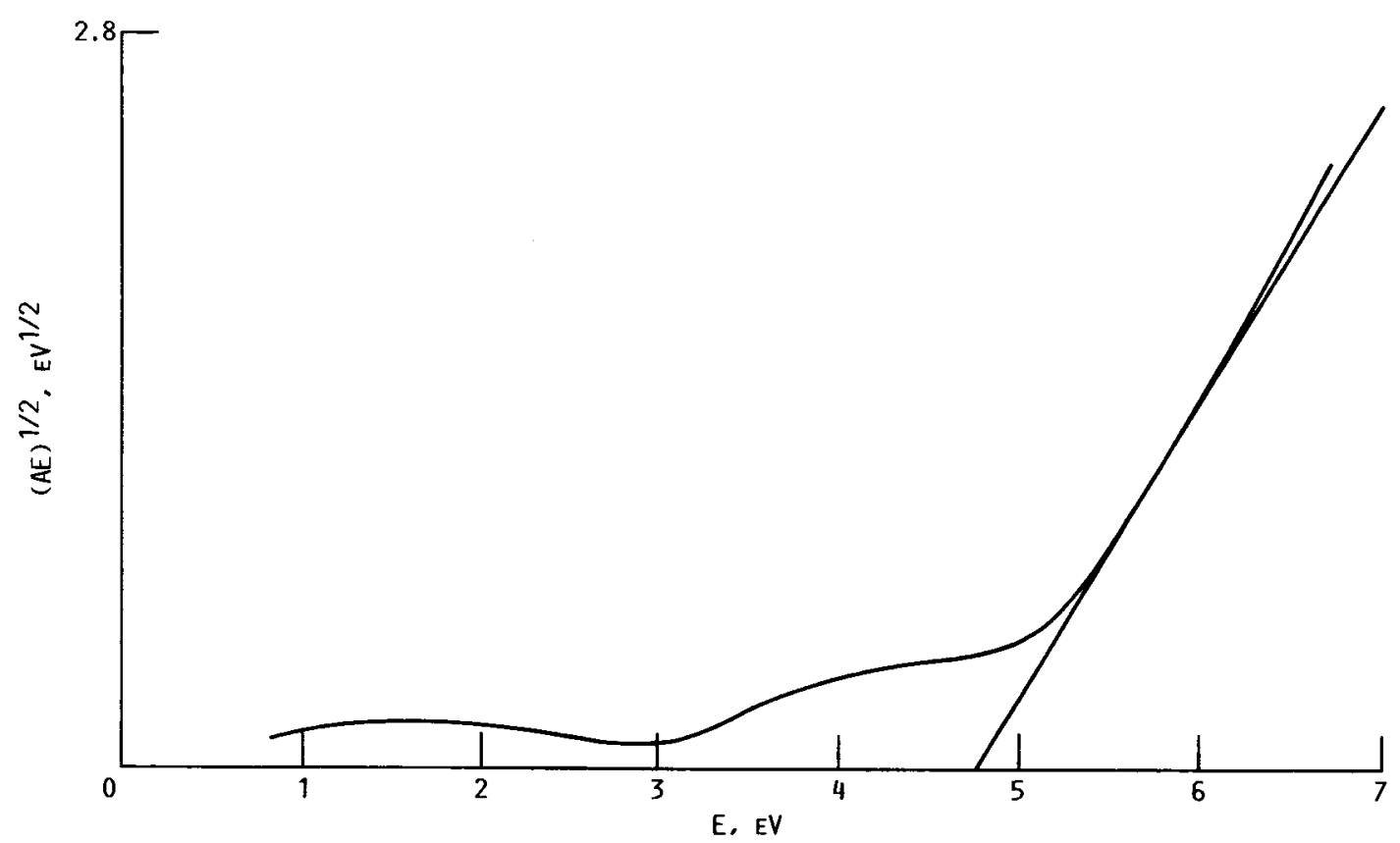

Figure 2. - tAUC PLOT, (AE) $)^{1 / 2}$ VERSUS E, FOR ION BEAM DEPOSITED BN-ON-QUARTZ. SUBSTRATE TEMPERATURE, $200{ }^{\circ} \mathrm{C}$; ION BEAM ENERGY, $500 \mathrm{EV}$.

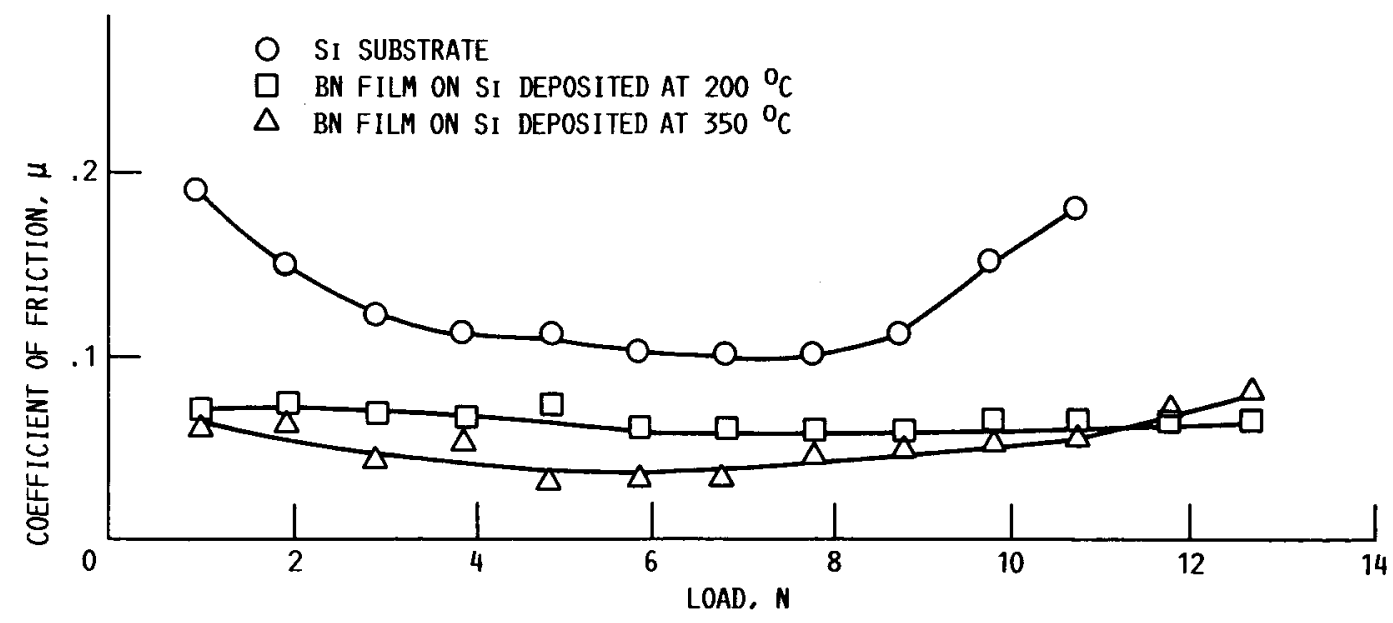

FIGURE 3. - COEFF ICIENT OF FRICTON VERSUS APPLIED LOAD. ION BEAM ENERGY, 150 EV: SLIDING VELOCITY, $12 \mathrm{MM} / \mathrm{MIN}$. 


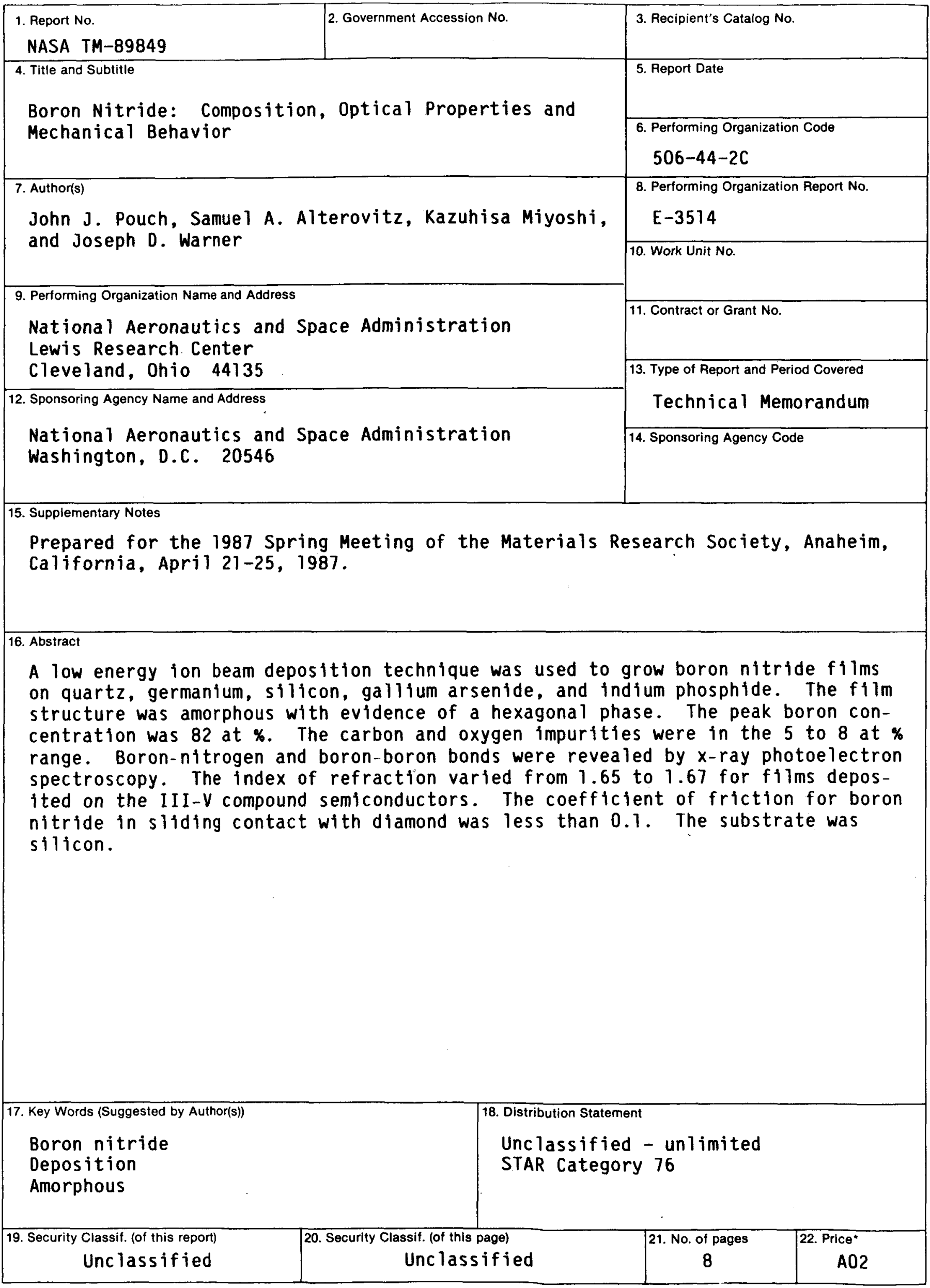

*For sale by the National Technical Information Service, Springfield, Virginia 22161 